\title{
Impact of Facility Surgical Volume on Survival in Patients With Cancer
}

\author{
Kelsey C. Stoltzfus, MPH${ }^{1}$; Biyi Shen, MS²; Leila Tchelebi, MD¹; Daniel M. Trifiletti, MD³; Niraj J. Gusani, MD²,4, \\ Vonn Walter, PhD 2,6 ; Ming Wang, $\mathrm{PhD}^{2}$; and Nicholas G. Zaorsky, MD, MS ${ }^{1,2}$
}

\begin{abstract}
Background: Increased facility surgical treatment volume is sometimes associated with improved survival in patients with cancer; however, published studies evaluating volume are heterogeneous and disparate in their patient inclusion and definition of volume. The purpose of this work was to evaluate uniformly the impact of surgical facility volume on survival in patients with cancer. Methods: The National Cancer Database was searched for patients diagnosed in 2004 through 2013 with the 12 cancers most commonly treated surgically. Facilities were stratified by 4 categories using the overall population (low, intermediate, high, and very high), each including $25 \%$ of patients, and then stratified by each individual disease site. Five-year postsurgery survival was estimated using both the KaplanMeier method and corresponding log-rank tests for group comparisons. Cox proportional hazard models were used to evaluate the effects of facility volume on 5-year postsurgery survival further, adjusted for multiple covariates. Results: A total of 3,923,618 patients who underwent surgery were included from 1,139 facilities. Of these, $40.4 \%$ had breast cancer, $12.8 \%$ prostate cancer, and $10.0 \%$ colon cancer. Most patients were female $(65.0 \%)$, White $(86.4 \%)$, and privately insured (51.6\%) with stage 0 -III disease (64.8\%). For all cancers, the risk of death for patients undergoing surgery at very high-volume facilities was $88 \%$ of that for those treated at low-volume facilities. Hazard ratios (HRs) were greatest (very high vs low volume) for cancer of the prostate (HR, $0.66 ; 95 \% \mathrm{Cl}, 0.63-0.69)$, pancreas (HR, $0.75 ; 95 \%$ $\mathrm{Cl}, 0.71-0.78)$, and esophagus ( $\mathrm{HR}, 0.78 ; 95 \% \mathrm{Cl}, 0.73-0.83)$, and for melanoma ( $\mathrm{HR}, 0.81 ; 95 \% \mathrm{Cl}, 0.78-0.84)$; differences were smallest for uterine and non-small cell lung cancers. Overall survival differences were greatest for cancers of the brain, pancreas, and esophagus. Conclusions: Patients treated surgically at higher-volume facilities consistently had improved overall survival compared with those treated at low-volume centers, although the magnitude of difference was cancer-specific.
\end{abstract}

J Natl Compr Canc Netw 2021;19(5):495-503 doi: 10.6004/jnccn.2020.7644

\footnotetext{
${ }^{1}$ Department of Radiation Oncology, Penn State Cancer Institute, and 2Department of Public Health Sciences, Penn State College of Medicine, Hershey, Pennsylvania; ${ }^{3}$ Department of Radiation Oncology, Mayo Clinic, Jacksonville, Florida; ${ }^{4}$ Department of Surgery, Penn State College of Medicine, Hershey, Pennsylvania; ${ }^{5}$ Section of Surgical Oncology, Baptist MD Anderson Cancer Center, Jacksonville, Florida; and ${ }^{6}$ Department of Biochemistry and Molecular Biology, Penn State College of Medicine, Hershey, Pennsylvania.
}

See JNCCN.org for supplemental online content.

\section{Background}

Patients with cancer treated surgically at high-volume, multidisciplinary centers are hypothesized to have improved outcomes and fewer toxicities from therapy than those treated at low-volume facilities. However, it is currently unknown which patients with cancer benefit most from treatment at high-volume facilities, and whether patients with certain cancers should preferentially be referred only to high-volume facilities, similar to the referral of patients to level 1 trauma centers for the management of serious injury or to stroke centers for the management of cerebral ischemia. ${ }^{1-3}$

NCCN recommends treatment at high-volume facilities for cancers of the pancreas and esophagus; however, there are minor or even no recommendations in the guidelines for other cancers, including breast and uterine, which are primarily treated with surgery. ${ }^{4}$ Furthermore, previous studies analyzing facility volume are heterogeneous, with differing patient populations, outcome measures, and volume classifications. Some of these studies have found a positive association between treatment at high-volume facilities and survival, ${ }^{5-7}$ whereas others have found little to no association. ${ }^{8,9}$ These differing results may be due to different methods of classifying facility volume and patient inclusion. Thus, there is a need to address these inconsistencies by using a uniform definition for facility volume classification across multiple cancer types and by using the same inclusion and exclusion criteria and outcome measure.

The purpose of our study was to evaluate the impact of surgical facility volume on survival in patients with cancer after surgery across multiple cancer sites. We hypothesized that patients receiving surgery at very high-volume facilities would have improved survival versus those treated at low-volume facilities. The results of this work may be used to identify disease sites that should be preferentially managed at highvolume surgical centers.

See page 577 for related commentary. 


\section{Methods}

The National Cancer Database (NCDB) is a hospitalbased cancer registry that collects data from American College of Surgeons' Commission on Cancer-accredited facilities. Recognized as the largest cancer registry worldwide, the database is sponsored by the American College of Surgeons and the American Cancer Society and includes $70 \%$ of all malignant cancers diagnosed in the United States. ${ }^{10}$ The NCDB contains data on all types of cancers, and records demographics, comorbidities, and overall survival. ${ }^{11-13}$ In addition, the NCDB contains information regarding therapies delivered during the first course of treatment, namely, surgery, radiation therapy, chemotherapy, hormone therapy, immunotherapy, and palliative care. Approximately 34 million cancer cases are included in the NCDB. ${ }^{12}$

We conducted a retrospective analysis of patients diagnosed in 2004 through 2013 with cancer of the following sites: breast, prostate, colon, melanoma, uterus, non-small cell lung, kidney, thyroid, bladder, rectum, brain, pancreas, and esophagus. These cancer sites were chosen because they had the highest incidence over the studied time period that were most commonly treated with a surgical approach. Patients were included if they received surgery as treatment of their cancer and had valid survival information available from 2004 through 2013; exclusion criteria included no surgery date in the patient record and male patients with breast cancer.

The NCDB reports the facility where the patient received care using a unique facility code. This facility code, available for all patients included in our analyses, was used to determine overall facility volume by cancer site. First, using the overall data not accounting for individual disease site, facilities were stratified into quartiles depending on the number of patients treated surgically at the facility over the study period. The quartiles were categorized as low-, intermediate-, high-, and very highvolume facilities. Second, for each individual cancer site, facilities were stratified into quartiles following the same process. For example, each quartile for breast cancer has approximately 396,000 patients treated surgically, yet the number of facilities in each quartile ranges from 90 to 625 . In addition, stratifying by individual disease site accounted for the possibility that one facility may surgically treat many patients with breast cancer, but only a small number of patients with esophageal cancer, for example. This method was chosen to create balanced group sizes by the number of patients treated. The primary outcome was 5-year postsurgery survival, which was chosen because it allowed us to examine both short- and long-term survival. Only facilities that were open and treating patients from 2004 through
2013, with complete volume data, were included in the analyses (supplemental eFigure 1, available with this article at JNCCN.org).

Five-year postsurgery survival was estimated using the Kaplan-Meier method and corresponding log-rank tests for group comparisons, and was defined as days from surgery to either death or 60 months postsurgery, whichever was earlier. Cox proportional hazards regression was used to perform a multivariable analysis by cancer site, adjusting for the following covariates: 4 age group levels based on quartiles, sex (male or female), race (White, Black, or other), insurance status (none, private, Medicaid, Medicare, or other government), clinical disease stage (0, I, II, III, IV, or unknown), urban/rural region (metropolitan, urban, or rural county), income level $(<\$ 38,000, \$ 38,000-\$ 47,999, \$ 48,000-\$ 62,999$, or $\geq \$ 63,000)$, Charlson-Deyo comorbidity score $(0,1,2$, or 3), facility type (community cancer, comprehensive community cancer, academic/research, or integrated network cancer program), radiation treatment (no, yes, or unknown), chemotherapy treatment (no, yes, or unknown), and distance traveled to facility. Patients with unknown values for any of these variables were excluded from the analysis. The reference group for all analyses was patients with stage I disease. In addition, to control for facility preference for handling a certain disease different from another facility, we conducted a hierarchical multilevel regression model with random effects on the facility level (eTable 1). All statistical analyses were performed with R version 3.5.1 (R Foundation for Statistical Computing), with 2-sided tests and statistical significance level of alpha $=0.05$.

\section{Results}

A total of 3,923,618 surgical patients were included (mean age, 62 years [range, 18-90 years]); of these, 1,584,815 (40.4\%) had breast cancer, 503,116 (12.8\%) had prostate cancer, and 394,229 (10.0\%) had colon cancer. Most patients were female $(65.0 \%)$, were White $(86.4 \%)$, had private insurance $(51.6 \%)$, and had stage 0 -III disease (64.8\%). Patients traveled an average of 30.9 miles to get to their treatment facility. These results are summarized in Table 1.

Surgical facility volume distribution for each cancer site is shown in Figure 1. Across all cancer sites studied, patients who received surgery from low-volume facilities (vs very high-volume) had the worst survival probability, followed by intermediate-volume, high-volume, and very high-volume facilities, as shown by the KaplanMeier plots in Figure 2. Regardless of cancer type, high-volume facilities had a higher proportion of observed survivors at 5 years postsurgery compared with low-volume facilities (83.6\% and $77.9 \%$, respectively). In addition, regardless of facility volume, at 5 years 


\section{Table 1. Patient Characteristics}

\begin{tabular}{|lc|}
\hline Characteristic & $\mathbf{n}(\%)$ \\
\hline Total, $\mathrm{N}$ & $3,923,618$ \\
\hline Age, $\mathrm{y}$ & $1,116,108(28.4)$ \\
\hline$<55$ & $1,094,078(27.9)$ \\
\hline $55-64$ & $903,847(23.0)$ \\
\hline $65-73$ & $809,558(20.6)$ \\
\hline$\geq 74$ & \\
\hline Sex & $1,372,755(35.0)$ \\
\hline Male & $2,550,863(65.0)$ \\
\hline Female & $3,388,683(86.4)$ \\
\hline Race & $362,361(9.2)$ \\
\hline White & $172,574(4.4)$ \\
\hline Black & \\
\hline Other & $88,523(2.3)$ \\
\hline Insurance status & $1,983,864(51.6)$ \\
\hline None & $165,556(4.3)$ \\
\hline Private insurance & $1,570,850(40.8)$ \\
\hline Medicaid & $39,109(1.0)$ \\
\hline Medicare & $1,156,494(29.5)$ \\
\hline Other government & $795,289(20.3)$ \\
\hline Cancer stage & $212,461(5.4)$ \\
\hline III & $109,843(2.8)$ \\
\hline Unknown & \\
\hline
\end{tabular}

(continued)

postsurgery, pancreatic cancer had the lowest proportion of observed survivors (average across all facility volumes, $32.0 \%$ ) and prostate cancer had the highest proportion (average across all facility volumes, 95.4\%). The largest difference between very high-volume and low-volume facilities in proportion of observed survivors at 5 years postsurgery was seen in brain cancer (difference, 18.5\%), whereas the smallest observed difference was seen in uterine and thyroid cancers ( $1.5 \%$ and $1.9 \%$, respectively) (Table 2). The log-rank test indicated significant differences in surgical survival probability between the 4 facility volume categories for all 13 cancers tested $(P<.01)$.

Once facilities were stratified by 4 categories (low-, intermediate-, high-, and very high-volume), a Cox regression analysis was conducted to determine whether surgical facility volume influenced 5-year postsurgery survival. For all sites, very high-volume facilities had significantly improved survival compared with lowvolume facilities (HR, 0.88; 95\% CI, 0.87-0.88). Patients

\section{Table 1. Patient Characteristics (cont.)}

\begin{tabular}{|lc|}
\hline Characteristic & $\mathbf{n}(\%)$ \\
\hline Region & $3,221,331(84.8)$ \\
\hline Metropolitan counties & $508,611(13.4)$ \\
\hline Urban counties & $68,446(1.8)$ \\
\hline Rural counties & $520,013(13.5)$ \\
\hline Income level (USD) & $766,890(19.9)$ \\
\hline$<\$ 38,000$ & $1,044,208(27.1)$ \\
\hline$\$ 38,000-\$ 47,999$ & $1,524,780(39.5)$ \\
\hline$\$ 48,000-\$ 62,999$ & \\
\hline$\geq \$ 63,000$ & $3,120,363(79.5)$ \\
\hline Charlson-Deyo comorbidity score & $634,637(16.2)$ \\
\hline 0 & $131,061(3.3)$ \\
\hline 1 & $37,557(1.0)$ \\
\hline 2 & \\
\hline 3 & $285,195(7.6)$ \\
\hline Facility type & $1,680,284(45.0)$ \\
\hline Community cancer program & $1,361,150(36.5)$ \\
\hline Comprehensive community cancer program & $406,605(10.9)$ \\
\hline Academic/Research program & $2,632,871(67.1)$ \\
\hline Integrated network cancer program & $1,251,441(31.9)$ \\
\hline No & $39,306(1.0)$ \\
\hline Yes & \\
\hline Unknown & \\
\hline Unknos & \\
\hline
\end{tabular}

with prostate cancer (HR, 0.66; 95\% CI, 0.63-0.69), pancreatic cancer (HR, 0.75; 95\% CI, 0.71-0.78), esophageal cancer (HR, 0.78; 95\% CI, 0.73-0.83), and melanoma (HR, 0.81; 95\% CI, 0.78-0.84) treated surgically at very high-volume facilities had the largest decrease in relative risk of death at 5 years postsurgery. Finally, compared with low-volume facilities, intermediatevolume facilities had statistically significantly improved survival for all cancer sites except thyroid cancer (Table 2). Results of the hierarchical multilevel regression model were similar to those of the Cox regression analysis.

The NCDB reports treatment occurring at the initial reporting facility, but patients may subsequently receive parts of their care (eg, chemotherapy, radiation therapy) at different facilities. In the analysis, we allowed patients to be included if their care was scattered among multiple facilities, to represent how real-world care is delivered. A downside to this technique is that the survival estimates may be biased from the care received at other facilities. 

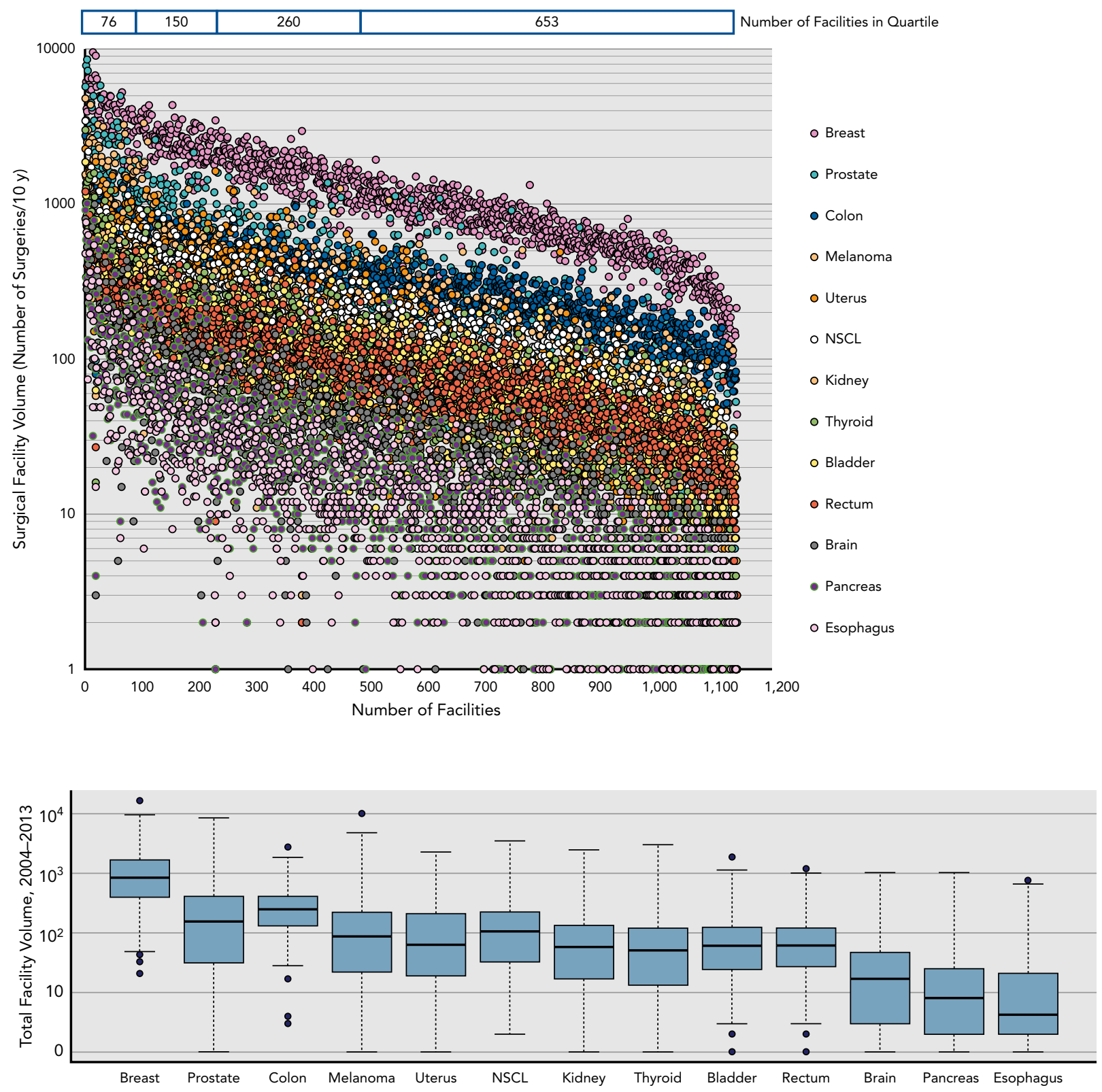

Figure 1. Facility volume distribution by cancer site. Plots were used to determine facility volume classification as low, intermediate, high, or very high for each cancer site.

Abbreviation: NSCL, non-small cell lung.

To mitigate this issue, we assessed a separate variable in the NCDB, namely CLASS_of_CASE, which allows investigators to evaluate whether care for a patient was performed at a single facility versus various facilities. We performed a sensitivity analysis for patients who received care at only one facility (CLASS_of_CASE values of 12 or 14; see supplemental eAppendix 1). In the sensitivity analysis, we found that $17 \%$ of patients were treated at a single facility, and the remainder received care that may have been performed at other facilities. The sensitivityadjusted HRs were similar, supporting our conclusion that care at a high-volume facility is associated with improved survival (supplemental eTables 1 and 2).

\section{Discussion}

This is the first study to examine the impact of surgical facility volume on survival among several cancer sites while adjusting for multiple covariates, with a uniform definition for surgical facility volume and consistent treatment inclusion and exclusion criteria and survival outcome measures. Patients receiving surgery at very high-volume versus low-volume facilities (ie, $\geq 898$ vs 

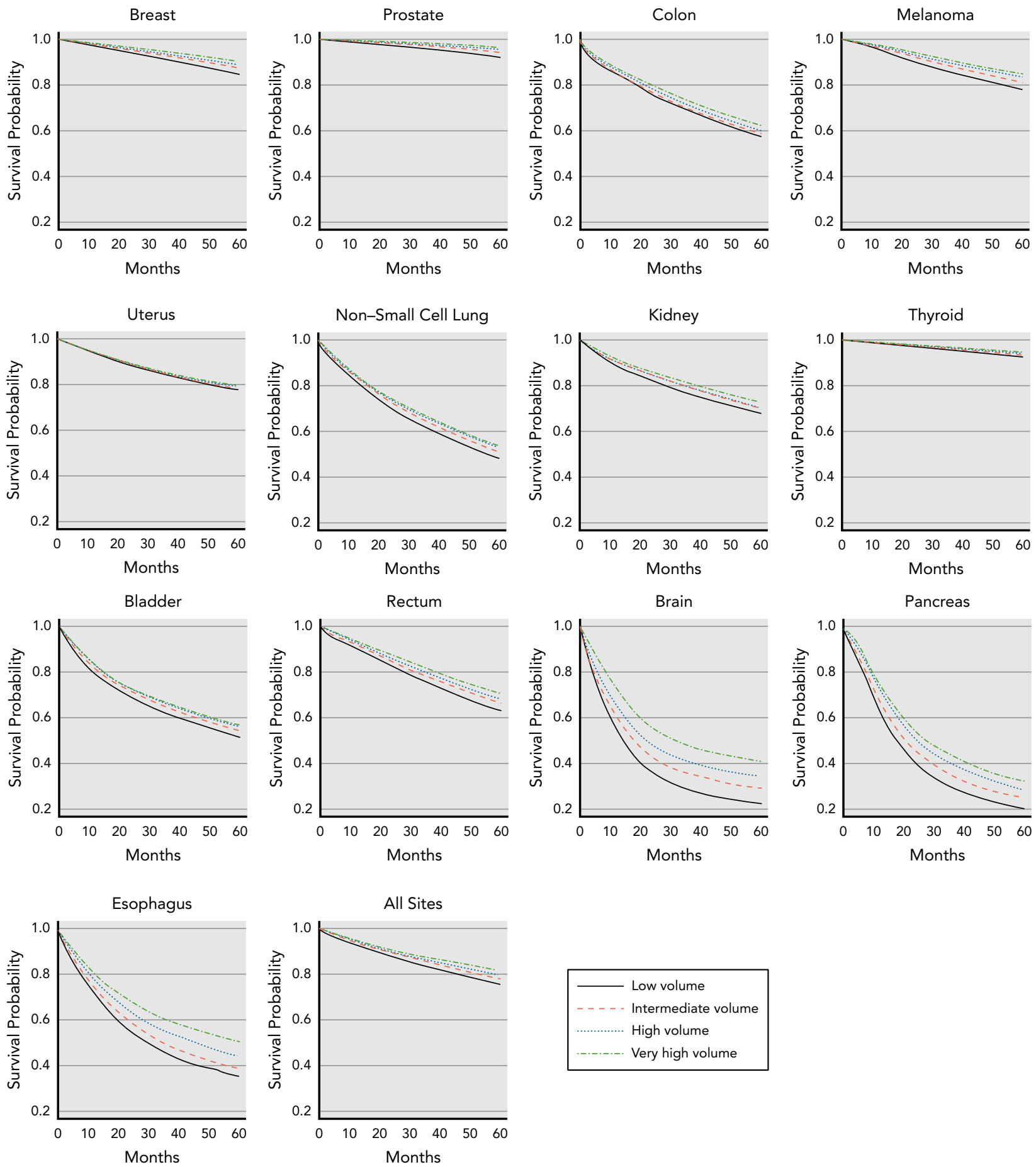

Figure 2. Kaplan-Meier survival curves of 5-year postsurgery survival, stratified by facility volume, for each cancer site.

$<275$ patients with cancer per year, respectively) have a higher proportion of observed survivors at 5 years postsurgery ( $83.6 \%$ vs $77.9 \%$, respectively). Risk of death for patients receiving surgery at very high-volume facilities is $88 \%$ of that for those treated at low-volume facilities, and the benefit appears on a gradient of facility volume.
Cancers that had the greatest absolute benefits tended to be those with the highest number of cancer-related deaths, including pancreas, esophagus, and brain. Results of this study may be used to support individual NCCN Clinical Practice Guidelines in Oncology in recommending surgical treatment at higher-volume facilities. 
Table 2. HRs and Proportion of Observed Survivors at 5 Years Postsurgery

\begin{tabular}{|c|c|c|c|c|c|c|c|c|}
\hline $\begin{array}{l}\text { Cancer } \\
\text { Site }\end{array}$ & $\begin{array}{l}\text { Facility Volume } \\
\text { Classification }^{\mathrm{a}}\end{array}$ & $\begin{array}{c}\text { Patients } \\
\text { n }\end{array}$ & $\begin{array}{c}\text { Facilities } \\
\mathbf{n}\end{array}$ & $\begin{array}{l}\text { Maximum Facility } \\
\text { Size in Group }\end{array}$ & $\begin{array}{l}\text { Patients Treated } \\
\text { Per Year, } \\
\text { Per Facility }\end{array}$ & $\begin{array}{c}\text { HR } \\
(95 \% \mathrm{Cl})^{b}\end{array}$ & $P$ Value & $\begin{array}{l}\text { Proportion of } \\
\text { Observed Survivors } \\
\text { at } 5 \text { Years }\end{array}$ \\
\hline \multirow[t]{3}{*}{ Alle } & Low & 981,687 & 653 & 2,743 & $<275$ & Ref & & $77.9 \%$ \\
\hline & High & 972,205 & 150 & 8,980 & $\geq 562$ and $<898$ & $0.91(0.90-0.91)$ & $<.0001$ & $81.6 \%$ \\
\hline & Very high & 987,134 & 76 & 45,666 & $\geq 898$ & $0.88(0.87-0.88)$ & $<.0001$ & $83.6 \%$ \\
\hline \multirow{2}{*}{ Breast $^{\mathrm{e}}$} & High & 394,010 & 163 & 3,007 & $\geq 197$ and $<299$ & $0.89(0.88-0.90)$ & $<.0001$ & $90.1 \%$ \\
\hline & Very high & 397,241 & 90 & 16,829 & $\geq 299$ & $0.84(0.82-0.85)$ & $<.0001$ & $91.6 \%$ \\
\hline \multirow[t]{2}{*}{ Prostate } & Low & 126,015 & 816 & 439 & $<44$ & Ref & & $93.3 \%$ \\
\hline & Intermediate & 126,416 & 188 & 983 & $\geq 44$ and $<99$ & $0.86(0.83-0.89)$ & $<.0001$ & $95.2 \%$ \\
\hline \multirow{2}{*}{ Colon } & High & 97,373 & 188 & 639 & $\geq 43$ and $<64$ & $0.94(0.92-0.96)$ & $<.0001$ & $63.5 \%$ \\
\hline & Very high & 99,278 & 115 & 2,764 & $\geq 64$ & $0.88(0.87-0.90)$ & $<.0001$ & $66.1 \%$ \\
\hline \multirow[t]{4}{*}{ Melanoma ${ }^{e}$} & Low & 77,469 & 849 & 250 & $\leq 25$ & Ref & & $81.1 \%$ \\
\hline & Intermediate & 77,192 & 192 & 682 & $>25$ and $<69$ & $0.89(0.86-0.91)$ & $<.0001$ & $83.9 \%$ \\
\hline & High & 76,588 & 73 & 1,862 & $\geq 69$ and $<187$ & $0.84(0.81-0.87)$ & $<.0001$ & $86.0 \%$ \\
\hline & Very high & 77,189 & 25 & 10,153 & $\geq 187$ & $0.81(0.78-0.84)$ & $<.0001$ & $87.3 \%$ \\
\hline \multirow[t]{3}{*}{ Uterus $^{e}$} & Low & 58,236 & 824 & 228 & $<23$ & Ref & & $80.2 \%$ \\
\hline & Intermediate & 58,309 & 167 & 494 & $\geq 23$ and $<50$ & $0.97(0.94-0.99)$ & .021 & $81.1 \%$ \\
\hline & High & 57,189 & 97 & 797 & $\geq 50$ and $<80$ & $0.96(0.93-0.99)$ & .022 & $81.4 \%$ \\
\hline \multirow{2}{*}{ Kidney ${ }^{f}$} & High & 36,682 & 114 & 484 & $\geq 24$ and $<49$ & $0.94(0.91-0.97)$ & $<.001$ & $74.1 \%$ \\
\hline & Very high & 37,306 & 46 & 2,481 & $\geq 49$ & $0.87(0.83-0.90)$ & $<.0001$ & $76.3 \%$ \\
\hline \multirow[t]{4}{*}{ Thyroidf } & Low & 35,205 & 781 & 114 & $<12$ & Ref & & $93.4 \%$ \\
\hline & Intermediate & 34,507 & 207 & 247 & $\geq 12$ and $<25$ & $0.93(0.87-0.99)$ & .029 & $94.3 \%$ \\
\hline & High & 34,568 & 108 & 489 & $\geq 25$ and $<49$ & $0.89(0.82-0.96)$ & .002 & $94.9 \%$ \\
\hline & Very high & 35,090 & 40 & 3,004 & $\geq 49$ & $0.82(0.75-0.89)$ & $<.0001$ & $95.3 \%$ \\
\hline \multirow[t]{4}{*}{ Bladder ${ }^{e}$} & Low & 33,157 & 684 & 96 & $<10$ & Ref & & $55.5 \%$ \\
\hline & Intermediate & 32,570 & 253 & 175 & $\geq 10$ and $<18$ & $0.94(0.92-0.97)$ & $<.0001$ & $58.1 \%$ \\
\hline & High & 32,434 & 140 & 327 & $\geq 18$ and $<33$ & $0.91(0.89-0.93)$ & $<.0001$ & $59.6 \%$ \\
\hline & Very high & 32,953 & 61 & 1,869 & $\geq 33$ & $0.86(0.83-0.89)$ & $<.0001$ & $60.5 \%$ \\
\hline \multirow[t]{4}{*}{ Rectume } & Low & 31,070 & 652 & 86 & $<9$ & Ref & & $66.9 \%$ \\
\hline & Intermediate & 30,384 & 260 & 159 & $\geq 9$ and $<16$ & $0.92(0.89-0.95)$ & $<.0001$ & $69.8 \%$ \\
\hline & High & 29,835 & 147 & 266 & $\geq 16$ and $<27$ & $0.87(0.84-0.90)$ & $<.0001$ & $71.8 \%$ \\
\hline & Very high & 30,611 & 80 & 1,205 & $\geq 27$ & $0.83(0.80-0.86)$ & $<.0001$ & $74.4 \%$ \\
\hline
\end{tabular}


Table 2. HRs and Proportion of Observed Survivors at 5-Years Postsurgery (cont.)

\begin{tabular}{|c|c|c|c|c|c|c|c|c|}
\hline $\begin{array}{l}\text { Cancer } \\
\text { Site }\end{array}$ & $\begin{array}{l}\text { Facility Volume } \\
\text { Classification }^{\mathrm{a}}\end{array}$ & $\begin{array}{c}\text { Patients } \\
\text { n }\end{array}$ & $\begin{array}{c}\text { Facilities } \\
\mathbf{n}\end{array}$ & $\begin{array}{l}\text { Maximum Facility } \\
\text { Size in Group }\end{array}$ & $\begin{array}{l}\text { Patients Treated } \\
\text { Per Year, } \\
\text { Per Facility }\end{array}$ & $\begin{array}{c}\text { HR } \\
(95 \% \mathrm{Cl})^{\mathrm{b}}\end{array}$ & $P$ Value ${ }^{c}$ & $\begin{array}{c}\text { Proportion of } \\
\text { Observed Survivors } \\
\text { at } 5 \text { Years }\end{array}$ \\
\hline \multirow[t]{3}{*}{ Braine } & Low & 14,537 & 797 & 53 & $<6$ & Ref & & $26.5 \%$ \\
\hline & High & 14,120 & 84 & 294 & $\geq 12$ and $<30$ & $0.88(0.85-0.91)$ & $<.0001$ & $38.0 \%$ \\
\hline & Very high & 14,720 & 32 & 1,023 & $\geq 30$ & $0.78(0.75-0.81)$ & $<.0001$ & $45.0 \%$ \\
\hline \multirow{3}{*}{ Pancreas ${ }^{9}$} & Intermediate & 9,892 & 152 & 121 & $>4$ and $<13$ & $0.89(0.86-0.93)$ & $<.0001$ & $30.4 \%$ \\
\hline & High & 9,901 & 56 & 258 & $\geq 13$ and $<26$ & $0.80(0.77-0.84)$ & $<.0001$ & $34.3 \%$ \\
\hline & Very high & 9,957 & 21 & 1,011 & $\geq 26$ & $0.75(0.71-0.78)$ & $<.0001$ & $37.7 \%$ \\
\hline \multirow[t]{2}{*}{ Esophagus ${ }^{9}$} & Low & 7,786 & 832 & 26 & $<3$ & Ref & & $39.9 \%$ \\
\hline & Intermediate & 7,590 & 185 & 71 & $\geq 3$ and $<8$ & $0.92(0.88-0.97)$ & $<.001$ & $43.0 \%$ \\
\hline
\end{tabular}

Abbreviations: HR, hazard ratio; NSCL, non-small cell lung.

aecommendations from NCCN. ${ }^{4}$

bObtained using Cox proportional multivariate analysis, adjusting for: age, sex, race, insurance status, cancer stage, urban/rural region, income level, comorbidity score, facility type, radiation, chemotherapy, and distance traveled to facility.

'Statistically significant at $P<.0012$

dObtained via Kaplan-Meier method.

eNCCN has no recommendation regarding facility volume for treatment.

${ }^{f} \mathrm{NCCN}$ recommends certain patients be treated a high-volume facility.

gNCCN has strong recommendation all patients be treated at high-volume facility.

The methodologies and findings of prior studies have been heterogeneous, and most studies only considered one disease site at a time. Furthermore, facility volume and survival outcomes are not defined similarly across studies, making it difficult for results to be compared across cancer sites. For example, to define high-volume facilities, Cheung et $\mathrm{al}^{14}$ grouped facilities into tertiles based on number of surgeries performed; they then divided the institutions into thirds, classifying the upper one-third as high-volume centers. In contrast, Lüchtenborg et $\mathrm{al}^{15}$ used the number of surgical resections per hospital in the year of diagnosis, then allocated patients into 5 hospital volume groups: $<70,70-99,100-129,130-149$, and $\geq 150$ procedures. Even though both studies included patients undergoing lung cancer surgery, volume was defined differently.

Some studies have found no association between survival and facility volume. In a study of patients with nonmetastatic malignant pleural mesothelioma, no independent effects on overall survival were observed when assessing facility volume. ${ }^{8}$ In addition, a study of patients with muscle-invasive bladder cancer found no difference in survival between patients treated at a high-volume versus low-volume facility (HR, 0.99; 95\% CI, 0.94-1.04). ${ }^{9}$ Mixed findings across different cancer sites may be the result of different definitions of facility volume, inclusion criteria, and outcome variables. Overall, the previous work is heterogeneous, making it difficult to extrapolate findings to multiple cancer sites.
Our study is the first analysis to examine multiple disease sites using a consistent definition for surgical facility volume, treatment, and survival outcomes.

Conversely, our study confirms the results of certain studies that have found a survival benefit with receiving care from a high-volume facility. ${ }^{16-19}$ For example, Chen et $\mathrm{a}^{20}$ showed that receiving treatment from a high-volume facility was associated with improved 90-day, 365- day, and 4 -year survival among patients with advanced-stage laryngeal cancer. Several other studies found similar findings of improved survival among patients with lung, cervical, and ovarian cancer being treated at high-volume facilities. ${ }^{14,15,21-23}$ Overall, multiple studies have demonstrated that facility volume seems to be a reliable predictor of survival following cancer treatment.

Surgical facility volume may not be a surrogate of physician volume, but rather may be a surrogate for services provided by the entire facility. Patients may appropriately receive definitive therapy through radiation and systemic therapy rather than undergoing surgery, thereby removing these patients from the at-risk pool. Patients who do undergo surgery may also be receiving early referrals to other physicians, such as radiation oncologists and medical oncologists, for opinions regarding definitive radiation therapy or early adjuvant therapy. ${ }^{24,25}$ Finally, high-volume facilities tend to have good advanced procedure care (eg, ICU care, postsurgical therapy), both preoperatively and postoperatively, including presurgery 
stress tests, visits with oncologists, and invasive postsurgery monitoring. ${ }^{26}$ These services may improve patients' quality of life and performance status before and after surgery, and may help to detect early recurrences or treatment failures. Thus, the Kaplan-Meier curves presented in our work are not simply shifted right for highvolume facilities (implying a delay to an eventual failure). Rather, their separation continues, and they have tails at 5 years, thus suggesting there is a durable improvement in survival at 5 years, a point considered synonymous with cure for most cancers.

This study has limitations. First, the NCDB is limited to first course of treatment, so patients who received surgery after their first course of treatment are not coded in the NCDB and could not be included in the current analysis. ${ }^{12}$ Second, we chose to focus on surgery as the primary treatment variable. For some patients, surgery may not have been the most appropriate course of treatment, and they should have received some alternative treatment such as chemoradiotherapy instead. In addition, there may be an exceptional surgeon performing most surgeries at a facility that is responsible for improved survival. ${ }^{27}$ However, there is no way to test these hypotheses given the data available.

We chose to include facilities for which complete volume data were available from 2004 through 2013. Although we were able to adjust for measured confounders in our statistical analyses, there were still many unmeasured confounders for which we could not account. These variables may include both surgical and nonsurgical factors that influence survival. Furthermore, these unknown confounders likely differ based on cancer site and may be responsible, in part, for the large differences in survival seen across all cancer types.

Annual facility volume can vary by year and affect facility designation. We chose to stratify facilities into quartiles depending on the number of patients treated surgically over the entire study period, presenting the average of the 10 years. Although we did not adjust for the potential fluctuation in annual facility volume, the overall number of patients treated on average is a good estimation, considering volume fluctuates for all facilities.
Furthermore, a facility should not be at high risk of moving up or down into a different quartile in a given year.

Another limitation is the large percentage of cases with an unknown clinical stage group (supplemental eTable 3), which were excluded from analyses. In the earlier years of the study cohort, the percentage of unknown cases ranged from $49.3 \%$ to $59.0 \%$. In the later years, this percentage decreased, ranging from $16.2 \%$ to $28.7 \%$. This decrease in unknown clinical stage group coding is likely the result of a change in reporting requirements. For cases reported from 2004 to 2007, clinical stage group was reported by the managing physician. Beginning in 2008, however, clinical stage group could be reported by the managing physician or pulled from the patient record, resulting in more complete patient records, and thus more patients available to include in the analyses.

\section{Conclusions}

Patients treated surgically at very high-volume facilities have improved survival compared with those treated at low-volume facilities. For all cancers, the risk of death for patients undergoing surgery at very high-volume facilities (ie, those treating $>898$ patients with cancer per year) was $88 \%$ of that for those treated at low-volume facilities (ie, those treating $<275$ patients with cancer per year). These results identified certain cancer types (eg, pancreas, esophagus, brain) that should be preferentially referred to facilities with higher surgical volume with the goal of improving overall survival.

Submitted December 12, 2019; accepted for publication August 19, 2020. Published online February 9, 2021

Author contributions: Study concept and design: All authors. Data acquisition, analysis, and interpretation: Shen, Walter, Wang, Zaorsky. Statistical analysis: Shen, Wang. Study supervision: Zaorsky. Manuscript preparation: Stoltzfus, Zaorsky. Critical revision of the manuscript for important intellectual content: All authors.

Disclosures: Dr. Trifiletti has disclosed that he receives grant/research support from Novocure. Dr. Zaorsky has disclosed that he receives support from the NIH (LRP 1 L30 CA231572-0), and the American Cancer Society-Tri State CEOs Against Cancer Clinician Scientist Development (CSDG-20-013-01-

CCE). The remaining authors have disclosed that they have not received any financial consideration from any person or organization to support the preparation, analysis, results, or discussion of this article.

Correspondence: Nicholas G. Zaorsky, MD, MS, Department of Radiation Oncology, Penn State Cancer Institute, 500 University Drive, Hershey, PA 17033 Email: nicholaszaorsky@gmail.com; nzaorsky@pennstatehealth.psu.edu

\section{References}

1. MacKenzie EJ, Rivara FP, Jurkovich GJ, et al. A national evaluation of the effect of trauma-center care on mortality. N Engl J Med 2006;354: 366-378.

2. Xian Y, Holloway RG, Chan PS, et al. Association between stroke center hospitalization for acute ischemic stroke and mortality. JAMA 2011;305: 373-380.

3. Bekelis K, Marth NJ, Wong K, et al. Primary stroke center hospitalization for elderly patients with stroke: implications for case fatality and travel times. JAMA Intern Med 2016;176:1361-1368.

4. NCCN Guidelines \& Clinical Resources: NCCN Guidelines. Accessed October 24, 2019. Available at: https://www.nccn.org/professionals/ physician_gls/default.aspx

5. Birkmeyer JD, Sun Y, Wong SL, et al. Hospital volume and late survival after cancer surgery. Ann Surg 2007;245:777-783.

6. Joshi SS, Handorf EA, Zibelman M, et al. Treatment facility volume and survival in patients with metastatic renal cell carcinoma: a registry-based analysis. Eur Urol 2018;74:387-393.

7. Go RS, Al-Hamadani M, Shah ND, et al. Influence of the treatment facility volume on the survival of patients with non-Hodgkin lymphoma. Cancer 2016;122:2552-2559.

8. Verma V, Ahern CA, Berlind CG, et al. Facility volume and postoperative outcomes for malignant pleural mesothelioma: A National Cancer Data Base analysis. Lung Cancer 2018;120:7-13. 
9. Bajaj A, Martin B, Bhasin R, et al. The impact of academic facility type and case volume on survival in patients undergoing curative radiation therapy for muscle-invasive bladder cancer. Int J Radiat Oncol Biol Phys 2018;100: 851-857.

10. Bilimoria KY, Stewart AK, Winchester DP, et al. The National Cancer Data Base: a powerful initiative to improve cancer care in the United States. Ann Surg Oncol 2008;15:683-690.

11. Boffa DJ, Rosen JE, Mallin K, et al. Using the National Cancer Database for outcomes research: a review. JAMA Oncol 2017;3:1722-1728.

12. American College of Surgeons. About the National Cancer Database. Accessed November 20, 2020. Available at: https://www.facs.org/Quality-Programs/Cancer/NCDB/about

13. Zaorsky NG, Zhang Y, Walter $V$, et al. Clinical trial accrual at initial course of therapy for cancer and its impact on survival. J Natl Compr Canc Netw 2019;17:1309-1316.

14. Cheung MC, Hamilton K, Sherman R, et al. Impact of teaching facility status and high-volume centers on outcomes for lung cancer resection: an examination of 13,469 surgical patients. Ann Surg Oncol 2009;16:3-13.

15. Lüchtenborg M, Riaz SP, Coupland VH, et al. High procedure volume is strongly associated with improved survival after lung cancer surgery. J Clin Oncol 2013;31:3141-3146.

16. Birkmeyer JD, Warshaw AL, Finlayson SR, et al. Relationship between hospital volume and late survival after pancreaticoduodenectomy. Surgery 1999;126:178-183.

17. Schrag $D$, Panageas $K S$, Riedel $E$, et al. Surgeon volume compared to hospital volume as a predictor of outcome following primary colon cancer resection. J Surg Oncol 2003;83:68-78, discussion 78-79.

18. Gutierrez JC, Perez EA, Moffat FL, et al. Should soft tissue sarcomas be treated at high-volume centers? An analysis of 4205 patients. Ann Surg 2007;245:952-958
19. Haque W, Verma V, Butler EB, et al. Trimodality therapy for esophagea cancer at high volume facilities is associated with improved postoperative outcomes and overall survival. Dis Esophagus 2019;32:doy067.

20. Chen AY, Fedewa S, Pavluck A, et al. Improved survival is associated with treatment at high-volume teaching facilities for patients with advanced stage laryngeal cancer. Cancer 2010;116:4744-4752.

21. Koshy M, Malik R, Mahmood U, et al. Stereotactic body radiotherapy and treatment at a high volume facility is associated with improved survival in patients with inoperable stage I non-small cell lung cancer. Radiother Oncol 2015;114:148-154

22. Lin JF, Berger JL, Krivak TC, et al. Impact of facility volume on therapy and survival for locally advanced cervical cancer. Gynecol Oncol 2014;132: 416-422.

23. Bristow RE, Palis BE, Chi DS, et al. The National Cancer Database repor on advanced-stage epithelial ovarian cancer: impact of hospital surgica case volume on overall survival and surgical treatment paradigm. Gyneco Oncol 2010;118:262-267

24. Goulart BH, Reyes CM, Fedorenko CR, et al. Referral and treatment patterns among patients with stages III and IV non-small-cell lung cancer. J Oncol Pract 2013;9:42-50.

25. Luo R, Giordano SH, Freeman JL, et al. Referral to medical oncology: crucial step in the treatment of older patients with stage III colon cancer Oncologist 2006;11:1025-1033.

26. Birkmeyer JD, Sun $Y$, Goldfaden $A$, et al. Volume and process of care in high-risk cancer surgery. Cancer 2006;106:2476-2481.

27. Birkmeyer JD, Stukel TA, Siewers AE, et al. Surgeon volume and operative mortality in the United States. N Engl J Med 2003;349:2117-2127.

\section{Explore Oncology From Every Angle}

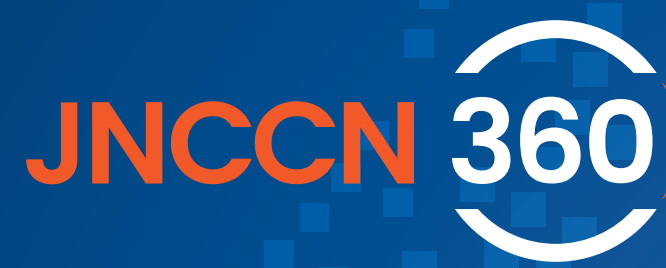

The Hub for Disease-Specific Clinical Information

> JNCCN Spotlights:

exclusive commentary

about current therapies

Video interviews with experts
Links to professional

and patient resources

Summaries of news

and medical literature
JNCCN360.org
\$IARBORSIDE

The nexus of knowledge
National Comprehensive Cancer 
Supplemental online content for:

\section{Impact of Facility Surgical Volume on Survival in Patients With Cancer}

Kelsey C. Stoltzfus, MPH; Biyi Shen, MS; Leila Tchelebi, MD; Daniel M. Trifiletti, MD; Niraj J. Gusani, MD; Vonn Walter, PhD; Ming Wang, PhD; and Nicholas G. Zaorsky, MD, MS

J Natl Compr Canc Netw 2021;19(5):495-503

eFigure 1: Chart Defining Complete Volume Data eTable 1: Comparison of Hazard Ratios From Original Versus Sensitivity Analysis eTable 2: Breakdown of Patients Treated at Various Institutions by "CLASS_OF_CASE" Value eTable 3: Distribution of Cases by Year of Diagnosis and Clinical Stage Group eAppendix 1: Sensitivity Analysis for Patients Treated at Only One Facility 


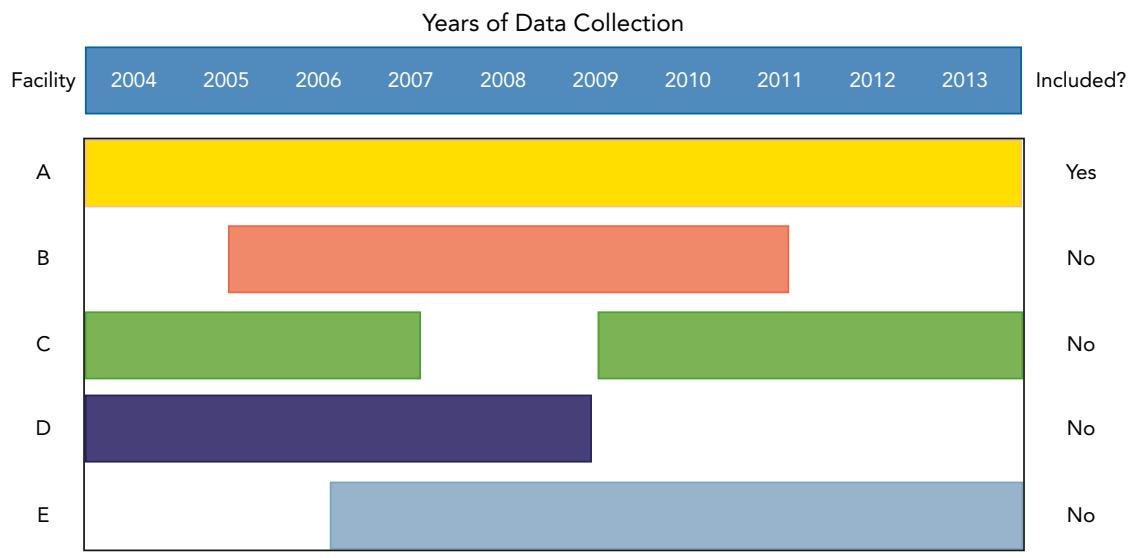

eFigure 1. Chart defining complete volume data. Only facilities that were open and treating patients from 2004-2013, with complete volume data, were included in the analyses. For example, facility A shows data collection continuously occurring from 2004-2013 and therefore was included in the analyses, whereas facilities B through $E$ have gaps in their data collection during this time period and therefore were excluded. 


\section{eTable 1. Comparison of HRs From Original Versus Sensitivity Analysis ${ }^{a}$}

\begin{tabular}{|c|c|c|c|c|}
\hline Cancer Site & Facility Volume Classification & $\begin{array}{c}\text { Original HR } \\
(95 \% \mathrm{Cl})^{\mathrm{b}}\end{array}$ & $\begin{array}{c}\text { Sensitivity Analysis HR } \\
(95 \% \mathrm{CI})\end{array}$ & $\begin{array}{l}\text { Sensitivity } \\
P \text { Value }\end{array}$ \\
\hline \multirow[t]{4}{*}{ Breast } & Low & Ref & Ref & \\
\hline & Intermediate & $0.93(0.92-0.95)$ & $0.87(0.84-0.91)$ & $<.0001$ \\
\hline & High & $0.89(0.88-0.90)$ & $0.85(0.82-0.89)$ & $<.0001$ \\
\hline & Very high & $0.84(0.82-0.85)$ & $0.80(0.77-0.84)$ & $<.0001$ \\
\hline \multirow[t]{3}{*}{ Prostate } & Low & Ref & Ref & \\
\hline & High & $0.77(0.74-0.80)$ & $0.75(0.74-0.80)$ & $<.0001$ \\
\hline & Very high & $0.66(0.63-0.69)$ & $0.74(0.67-0.83)$ & $<.0001$ \\
\hline \multirow[t]{3}{*}{ Colon } & Low & Ref & Ref & \\
\hline & Intermediate & $0.97(0.95-0.98)$ & $0.97(0.95-0.99)$ & $<.001$ \\
\hline & High & $0.94(0.92-0.96)$ & $0.92(0.91-0.94)$ & $<.0001$ \\
\hline \multirow{2}{*}{ NSCL } & High & $0.92(0.90-0.94)$ & $0.92(0.89-0.93)$ & $<.0001$ \\
\hline & Very high & $0.92(0.90-0.94)$ & $0.88(0.84-0.93)$ & $<.0001$ \\
\hline \multirow[t]{4}{*}{ Melanoma } & Low & Ref & Ref & \\
\hline & Intermediate & $0.89(0.86-0.91)$ & $0.88(0.82-0.96)$ & $<.0001$ \\
\hline & High & $0.84(0.81-0.87)$ & $0.85(0.78-0.94)$ & $<.0001$ \\
\hline & Very high & $0.81(0.78-0.84)$ & $0.72(0.66-0.81)$ & $<.0001$ \\
\hline \multirow[t]{4}{*}{ Kidney } & Low & Ref & Ref & \\
\hline & Intermediate & $0.95(0.92-0.98)$ & $0.98(0.91-1.05)$ & .58 \\
\hline & High & $0.94(0.91-0.97)$ & $0.94(0.88-1.01)$ & .13 \\
\hline & Very high & $0.87(0.83-0.90)$ & $0.86(0.79-0.93)$ & $<.0001$ \\
\hline \multirow{2}{*}{ Thyroid } & High & $0.89(0.82-0.96)$ & $1.03(0.86-1.24)$ & .74 \\
\hline & Very high & $0.82(0.75-0.89)$ & $0.78(0.63-0.97)$ & .02 \\
\hline \multirow[t]{4}{*}{ Bladder } & Low & Ref & Ref & \\
\hline & Intermediate & $0.94(0.92-0.97)$ & $0.97(0.91-1.02)$ & .25 \\
\hline & High & $0.91(0.89-0.93)$ & $0.89(0.84-0.95)$ & $<.0001$ \\
\hline & Very high & $0.86(0.83-0.89)$ & $0.85(0.79-0.90)$ & $<.0001$ \\
\hline \multirow[t]{4}{*}{ Rectum } & Low & Ref & Ref & \\
\hline & Intermediate & $0.92(0.89-0.95)$ & $0.90(0.82-1.00)$ & .91 \\
\hline & High & $0.87(0.84-0.90)$ & $0.89(0.80-0.99)$ & .03 \\
\hline & Very high & $0.83(0.80-0.86)$ & $0.74(0.66-0.82)$ & $<.0001$ \\
\hline
\end{tabular}

Abbreviations: HR, hazard ratio; NSCL, non-small cell lung.

aWith CLASS_OF_CASE values of only 12 or 14 .

bObtained using Cox proportional multivariate analysis, adjusting for: age, sex, race, insurance status, cancer stage, urban/rural region, income level, comorbidity score, facility type, radiation, chemotherapy, and distance traveled to facility.

'Statistically significant at $P<.0012$. 
eTable 2. Breakdown of Patients Treated at Various Institutions by "CLASS_OF_CASE" Value

\begin{tabular}{|c|c|c|c|c|c|c|c|c|c|c|c|c|}
\hline & 0 & 10 & 11 & 12 & 13 & 14 & 20 & 21 & 22 & $12+14$ & $\underset{\text { All }}{\text { Sum of }}$ & $\begin{array}{c}\% \\
(12+14) / A l l\end{array}$ \\
\hline Bladder & 886 & 53,512 & 3,714 & 9,583 & 6,852 & 27,861 & 24,196 & 13,184 & 7,974 & 37,444 & 147,762 & 0.253408 \\
\hline Breast & 36,219 & 639,720 & 36,971 & 24,528 & 170,349 & 256,377 & 326,626 & 196,954 & 79,222 & 280,905 & $1,766,966$ & 0.158976 \\
\hline Colon & 6,829 & 188,218 & 5,338 & 10,657 & 20,427 & 76,587 & 71,815 & 26,282 & 26,172 & 87,244 & 432,325 & 0.201802 \\
\hline NSCL & 7,946 & 102,335 & 1,059 & 2,641 & 13,576 & 54,600 & 42,844 & 12,311 & 19,152 & 57,241 & 256,464 & 0.223193 \\
\hline Melanoma & 1,199 & 72,044 & 11,645 & 14,238 & 3,571 & 34,336 & 113,416 & 61,964 & 35,831 & 48,574 & 348,244 & 0.139483 \\
\hline Pancreas & 2,048 & 13,641 & 172 & 201 & 4,807 & 9,486 & 7,422 & 4,467 & 3,814 & 9,687 & 46,058 & 0.210322 \\
\hline Prostate & 6,432 & 150,974 & 10,253 & 62,179 & 2,964 & 34,767 & 176,617 & 18,835 & 80,999 & 96,946 & 544,020 & 0.178203 \\
\hline Total & & & & & & & & & & 769,248 & $4,361,483$ & 0.176373 \\
\hline
\end{tabular}

Abbreviation: NSCL, non-small cell lung. 


\section{eTable 3. Distribution of Cases by Year of Diagnosis and Clinical Stage Group}

\begin{tabular}{|lcccccrrrrr|}
\hline Clinical Cancer Stage & $\mathbf{2 0 0 4}$ & $\mathbf{2 0 0 5}$ & $\mathbf{2 0 0 6}$ & $\mathbf{2 0 0 7}$ & $\mathbf{2 0 0 8}$ & $\mathbf{2 0 0 9}$ & $\mathbf{2 0 1 0}$ & $\mathbf{2 0 1 1}$ & $\mathbf{2 0 1 2}$ & $\mathbf{2 0 1 3}$ \\
\hline O & 21,818 & 22,853 & 24,107 & 27,293 & 38,946 & 43,788 & 46,018 & 47,767 & 49,983 & 52,415 \\
\hline I & 49,671 & 54,494 & 59,138 & 71,661 & 114,760 & 132,938 & 160,985 & 169,700 & 169,589 & 173,558 \\
\hline II & 46,376 & 51,407 & 59,405 & 72,401 & 97,004 & 103,228 & 91,770 & 92,432 & 89,010 & 92,256 \\
III & 12,838 & 14,264 & 15,608 & 17,754 & 23,307 & 24,706 & 26,267 & 25,795 & 25,836 & 26,086 \\
\hline IV & 6,686 & 7,093 & 7,426 & 8,443 & 12,088 & 12,784 & 13,903 & 13,763 & 13,709 & 13,948 \\
\hline Unknown & 197,309 & 199,263 & 204,067 & 191,987 & 115,395 & 88,610 & 67,666 & 71,044 & 69,802 & 69,400 \\
\hline Percent unknown & $59.0 \%$ & $57.0 \%$ & $55.2 \%$ & $49.3 \%$ & $28.7 \%$ & $21.8 \%$ & $16.6 \%$ & $16.9 \%$ & $16.7 \%$ & $16.2 \%$ \\
\hline
\end{tabular}

aReporting rules changed, allowing clinical stage to be reported by managing physician or pulled from patient record. 


\section{eAppendix 1: Sensitivity Analysis for Patients Treated at Only One Facility}

Regarding the delivery of all treatments "at the reporting facility," there is a variable to assess where treatments were performed, "CLASS_OF_CASE," with the values shown below. Approximately $17 \%$ of patients were treated solely at a single institution, whereas treatment for the remainder may have included at least one other institution. To capture only treatments performed at the same institution, we conducted a sensitivity analysis and included only cases with values of 12 and 14. Overall, the sensitivity analysis hazard ratios were similar to those of the original analysis.

\begin{tabular}{|ll|}
\hline Code & Definition \\
\hline 00 & Initial diagnosis at the reporting facility and all treatment or a decision not to treat was done elsewhere \\
\hline 10 & Initial diagnosis at the reporting facility, and part or all of first course treatment or a decision not to treat was done at the reporting facility, NOS \\
11 & Initial diagnosis in a staff physician's office and part of first course treatment was done at the reporting facility \\
\hline 12 & Initial diagnosis in a staff physician's office and all of first course treatment or a decision not to treat was done at the reporting facility \\
\hline 13 & Initial diagnosis and part of first course treatment was done at the reporting facility; part of first course treatment was done elsewhere \\
\hline 20 & Initial diagnosis and all of first course treatment or a decision not to treat was done at the reporting facility \\
\hline 21 & Initial diagnosis elsewhere and all or part of first course treatment or a decision not to treat was done at the reporting facility, NOS \\
\hline 22 & Initial diagnosis elsewhere and all of first course treatment or a decision not to treat was done at the reporting facility \\
\hline
\end{tabular}

Abbreviation: NOS, not otherwise specified. 